\title{
ADEQUAÇÃO DOS CARDÁPIOS DE UMA UNIDADE DE ALIMENTAÇÃO EM RELAÇÃO AO PROGRAMA DE ALIMENTAÇÃO DO TRABALHADOR
}

\author{
MENU ADEQUACY IN A FOOD SERVICE RESTAURANT IN RELATION TO A MEAL PROGRAM \\ FOR WORKERS
}

\author{
Marianne Pinheiro da Rocha ${ }^{1}$ \\ Andrea Carvalheiro Guerra Matias ${ }^{2}$ \\ Mônica Glória Neumann Spinelli ${ }^{2}$ \\ Edeli Simioni de Abreu²
}

Resumo: Uma alimentação adequada em uma Unidade de Alimentação e Nutrição (UAN) é essencial para a promoção da saúde do trabalhador e está associada ao aumento da produtividade e redução dos riscos de acidentes de trabalho. Este estudo teve como objetivo avaliar os cardápios do almoço dos funcionários de uma UAN inserida em um hospital de São Paulo conforme as exigências do Programa de Alimentação ao Trabalhador (PAT). Foram coletados dados dos cardápios de almoço durante uma semana e analisados valor calórico total, macronutrientes, NDPCal\%, sódio e fibras, e avaliados conforme os parâmetros do PAT (2006). Foi encontrado um valor calórico médio de 1375 kcal, resultado superior ao preconizado na legislação vigente. O percentual de carboidratos esteve abaixo e o de proteína, NDPCal\% e lipídios acima do recomendado. Os valores de fibra encontram-se acima dos valores preconizados. De modo geral, é necessária uma melhor elaboração dos cardápios, levando em conta as recomendações nutricionais do PAT, já que visam à saúde do trabalhador.

Palavras-chave: alimentação coletiva; saúde do trabalhador; planejamento de cardápio.

\begin{abstract}
Adequate food in a Food Service is essential for the promotion of workers' health and is associated with increased productivity and reduced risk of accidents. This study aimed to evaluate the employees'lunch menus in a hospital Food Service in São Paulo and the requirements of the Food Program for Workers. Lunch menu data were collected during a week, and total calorie content, macronutrients, NDPCal\%, sodium, and fiber according to the parameters of the Workers' Food Program was analized. An average caloric value of $1375 \mathrm{kcal}(S D \pm 192.9)$ was found. The proteins and lipids were above the recommendations, and percentage of carbohydrates was below the recommended requirements. The values of fiber and NDPCal\% were also inadequate. Thus, better menu planning is necessary that takes into account the nutritional recommendations of the Food Program for Workers to improving workers' health.
\end{abstract}

Keywords: collective feeding; occupational health; menu planning.

\footnotetext{
1 Mestranda do Programa de pós-graduação em Saúde Pública - Universidade de São Paulo - USP. E-mail: marianne_rocha@msn.com.

2 Doutora em Saúde Pública - USP e Professora da Universidade Presbiteriana Mackenzie - UPM. E-mails: acgmatias@gmail.com; monicaspi404@gmail.com; edeli@mackenzie.br.

Revista Univap - revista.univap.br

São José dos Campos-SP-Brasil, v. 20, n. 35, jul.2014. ISSN 2237-1753
} 


\section{INTRODUÇÃO}

Uma alimentação adequada em uma Unidade de Alimentação e Nutrição (UAN) é essencial para a promoção da saúde do trabalhador e para a boa execução de suas funções, visto que está associada ao aumento da produtividade e redução dos riscos de acidentes de trabalho (MATTOS, 2008).

Assim, foi instituído o Programa de Alimentação do Trabalhador (PAT) pela Lei 6.321, de 14/4/1976, com a finalidade de melhorar as condições nutricionais dos trabalhadores, especialmente aqueles com baixa renda que ganham até 5 salários mínimos por mês, visando a melhorias na qualidade de vida, diminuição de acidentes de trabalho, aumento da produtividade e prevenção de doenças (SAVIO et al., 2005).

Segundo o PAT, o almoço e jantar devem possuir de 600-800 kcal; já, as refeições menores, como desjejum e lanche da tarde, devem conter $300-400 \mathrm{kcal}$ e o percentual proteico-calórico (NdPCal) deverá ser, no mínimo, de 6\% (BRASIL, 2006).

Além disso, o cardápio deve ser equilibrado nutricionalmente, verificando-se a quantidade ofertada de alimentos e a inclusão de um alimento de cada grupo alimentar (energéticos, construtores e reguladores) na refeição (SAVIO et al., 2005).

Estudos têm demonstrado que o PAT não tem atingido o objetivo de promoção de saúde, visto que há uma oferta excessiva de lipídios e energia, além de uma alta prevalência de trabalhadores beneficiados pelo programa com dislipidemia e obesidade (GERALDO; BANDONI; JAIME, 2008).

A avaliação da distribuição dos macronutrientes em cardápios é importante para melhorar a qualidade de vida e produtividade do trabalhador, visto as exigências do PAT, as recomendações da Organização Mundial da Saúde (OMS) para a prevenção de doenças crônicas não transmissíveis, e a promoção de uma alimentação balanceada (SOUSA; SILVA; FERNANDES, 2009).

Dessa forma, o objetivo deste estudo foi avaliar o valor nutricional da oferta de cardápios da refeição almoço dos funcionários de uma UAN inserida em um hospital particular da cidade de São Paulo, segundo as exigências do PAT.

\section{METODOLOGIA}

Trata-se de um estudo transversal que foi realizado em uma Unidade de Alimentação e Nutrição situada na zona sul, na cidade de São Paulo, SP, com média de 600 refeições servidas no almoço.

A coleta de dados foi realizada no primeiro semestre de 2012. Foram coletados dados dos cardápios de almoço, durante uma semana, a partir da quantificação per capita dos alimentos e preparações fornecidas pela empresa. Os per capita dos alimentos foram obtidos por meio da ficha de requisição feita aos fornecedores pela UAN, com ajustes de fator de correção segundo Ornellas (2006).

Devido a UAN servir dois tipos de pratos proteicos, o per capita para o cálculo dos cardápios 
foi obtido pela sua média. Com relação à sobremesa, considerou-se a de maior aceitação.

Foram calculados o valor calórico total, macronutrientes, assim como gorduras saturadas, fibras, NDPCal\% e o teor de sódio dos cardápios, com auxílio do software Avanutriß, versão online (2012).

Para análise dos cardápios, foram utilizados os parâmetros exigidos pelo PAT, na Portaria Interministerial № 66/06 (BRASIL, 2006). Esse documento prevê para uma dieta de 2000 kcal, que o almoço deve conter $60 \%$ de carboidratos, $15 \%$ de proteínas, $25 \%$ de gorduras totais, quantidade inferior a $10 \%$ de gorduras saturadas, $4-5 \mathrm{~g}$ de fibras, 360-480 mg de sódio e valor energético entre 600-800 kcal, podendo haver acréscimo de 20\% (BRASIL, 2006).

Os dados coletados foram tabulados e apresentados por meio da distribuição das variáveis em medidas de posição e dispersão com o auxílio do software Microsoft Office Excel®, versão 2010.

\section{RESULTADOS E DISCUSSÃO}

A composição dos cardápios é apresentada no Quadro 1.

Quadro 1 - Descrição do cardápio semanal (5 dias). São Paulo, SP, 2012

\begin{tabular}{|c|c|c|c|c|c|}
\hline & 2ª-Feira & 3ㅁ- Feira & 4-Feira & 5a-Feira & 6a-Feira \\
\hline $\begin{array}{l}\text { PRATO } \\
\text { PRINCIPAL }\end{array}$ & $\begin{array}{c}\text { Filé de carne } \\
\text { grelhado }\end{array}$ & $\begin{array}{l}\text { Filé de } \\
\text { merluza no } \\
\text { fubá }\end{array}$ & Bife de panela & Rolê de frango & $\begin{array}{c}\text { Estrogonofe } \\
\text { de frango }\end{array}$ \\
\hline $\begin{array}{l}\text { PRATO } \\
\text { PRINCIPAL }\end{array}$ & $\begin{array}{l}\text { Linguiça de } \\
\text { frango } \\
\text { acebolada }\end{array}$ & $\begin{array}{c}\text { Carne em } \\
\text { cubos com } \\
\text { batata }\end{array}$ & $\begin{array}{l}\text { Isca de frango } \\
\text { à chinesa }\end{array}$ & $\begin{array}{c}\text { Conchiglia } \\
\text { calabresa com } \\
\text { queijo }\end{array}$ & Bife grelhado \\
\hline GUARNIÇÃO & $\begin{array}{l}\text { Creme de } \\
\text { espinafre }\end{array}$ & $\begin{array}{c}\text { Cenoura com } \\
\text { ervas }\end{array}$ & Purê misto & $\begin{array}{l}\text { Seleta de } \\
\text { legumes }\end{array}$ & Batata palha \\
\hline SALADA 1 & $\begin{array}{c}\text { Alface } \\
\text { americana }\end{array}$ & $\begin{array}{l}\text { Agrião com } \\
\text { milho }\end{array}$ & Alface crespa & Almeirão & Escarola \\
\hline SALADA 2 & $\begin{array}{c}\text { Tomate com } \\
\text { salsa }\end{array}$ & Tabule & $\begin{array}{l}\text { Berinjela ao } \\
\text { forno }\end{array}$ & Lentilha & $\begin{array}{c}\text { Abóbora seca } \\
\text { com salsa }\end{array}$ \\
\hline SALADA 3 & Grãos colorida & Beterraba & $\begin{array}{c}\text { Soja ao } \\
\text { vinagrete }\end{array}$ & Tomate & Pepino \\
\hline SOBREMESA & $\begin{array}{c}\text { Gelatina de } \\
\text { abacaxi }\end{array}$ & Curau & Mamão & $\begin{array}{l}\text { Pudim de } \\
\text { morango com } \\
\text { calda de } \\
\text { groselha }\end{array}$ & $\begin{array}{l}\text { Bolo mousse } \\
\text { de maracujá }\end{array}$ \\
\hline OPÇÃO & Melão & $\begin{array}{l}\text { Gelatina } \\
\text { morango }\end{array}$ & Gelatina limão & Banana & $\begin{array}{c}\text { Gelatina } \\
\text { morango }\end{array}$ \\
\hline SUCO & Uva & Limão & Laranja & Caju & Uva \\
\hline PRATO BASE & $\begin{array}{l}\text { Arroz } \\
\text { Feijão }\end{array}$ & $\begin{array}{l}\text { Arroz } \\
\text { Feijão }\end{array}$ & $\begin{array}{l}\text { Arroz } \\
\text { Feijão }\end{array}$ & $\begin{array}{l}\text { Arroz } \\
\text { Feijão }\end{array}$ & $\begin{array}{l}\text { Arroz } \\
\text { Feijão }\end{array}$ \\
\hline
\end{tabular}

Verificou-se que não foi ofertada fruta todos os dias, conforme o PAT recomenda. O baixo consumo de frutas está associado a um maior risco de doenças crônicas não transmissíveis (BRASIL, 2006; JAIME et al., 2007).

A variada oferta de hortaliças está de acordo com as recomendações do Guia Alimentar para 
a População Brasileira, no qual recomenda-se no mínimo uma porção de legume ou verdura na refeição. As hortaliças têm um papel importante na prevenção de doenças crônicas não transmissíveis, uma vez que são fontes de vitaminas, minerais e fibras (BRASIL, 2005).

Estudos demonstram que a população brasileira tem um baixo consumo de frutas e hortaliças e, também, há uma baixa oferta desses alimentos em restaurantes (SAVIO et al., 2005).

Na Tabela 1, são apresentados valor energético, percentual de macronutrientes e quantidade de fibras, e sódio dos cardápios analisados.

Tabela 1 - Estatística descritiva do valor energético, percentual de macronutrientes, quantidade de fibras, NdpCal\% e de sódio dos cardápios. São Paulo, 2012

\begin{tabular}{lcccc}
\hline \multicolumn{1}{c}{ Nutriente } & Média & $\begin{array}{c}\text { Desvio } \\
\text { Padrão }\end{array}$ & $\begin{array}{c}\text { Valor } \\
\text { Máximo }\end{array}$ & Valor Mínimo \\
\hline Energia (kcal) & 1375 & 193 & 1568 & 1126 \\
Carboidratos (\%) & 51,7 & 11,5 & 66,8 & 42,7 \\
Proteínas (\%) & 22,8 & 5,4 & 27,1 & 15,4 \\
Gorduras totais (\%) & 30,1 & 7,4 & 50,8 & 16,2 \\
Gorduras saturadas (\%) & 15,6 & 7,4 & 32,8 & 17,5 \\
NdpCal\% & 14,3 & 3,7 & 17,1 & 9,2 \\
Fibras (g) & 12,1 & 3,2 & 16,1 & 7,1 \\
Sódio (mg) & 613 & 494 & 1595 & 317 \\
\hline
\end{tabular}

Dessa forma, observa-se uma grande variação entre os valores nutricionais dos cardápios ofertados, decorrentes das diferentes preparações e os variados ingredientes utilizados.

A análise da energia revelou um valor calórico médio de $1375 \mathrm{kcal}$, resultado superior ao recomendado pelo PAT (BRASIL, 2006), de 600-800 kcal mesmo admitindo-se o acréscimo de $20 \%$.

Em estudo feito em indústrias petroquímicas participantes do PAT também foi encontrada uma oferta calórica acima da recomendada, atendendo a 96,1\% das necessidades energéticas diárias dos indivíduos (VELOSO; SANTANA; OLIVEIRA, 2007).

Esse dado é preocupante, visto que o excesso de calorias na dieta é relacionado ao excesso de peso e, consequentemente, a doenças, como hipertensão arterial, dislipidemias, diabetes mellitus, doenças cardiovasculares e câncer (GHISLANDI et al., 2007).

No Gráfico 1, é apresentada a comparação dos percentuais médios dos macronutrientes entre a UAN estudada e as recomendações do PAT. 


\section{Quadro 1 - Comparação dos percentuais recomendados pelo PAT com a média dos macronutrientes encontrados nos cardápios. São Paulo, 2012}

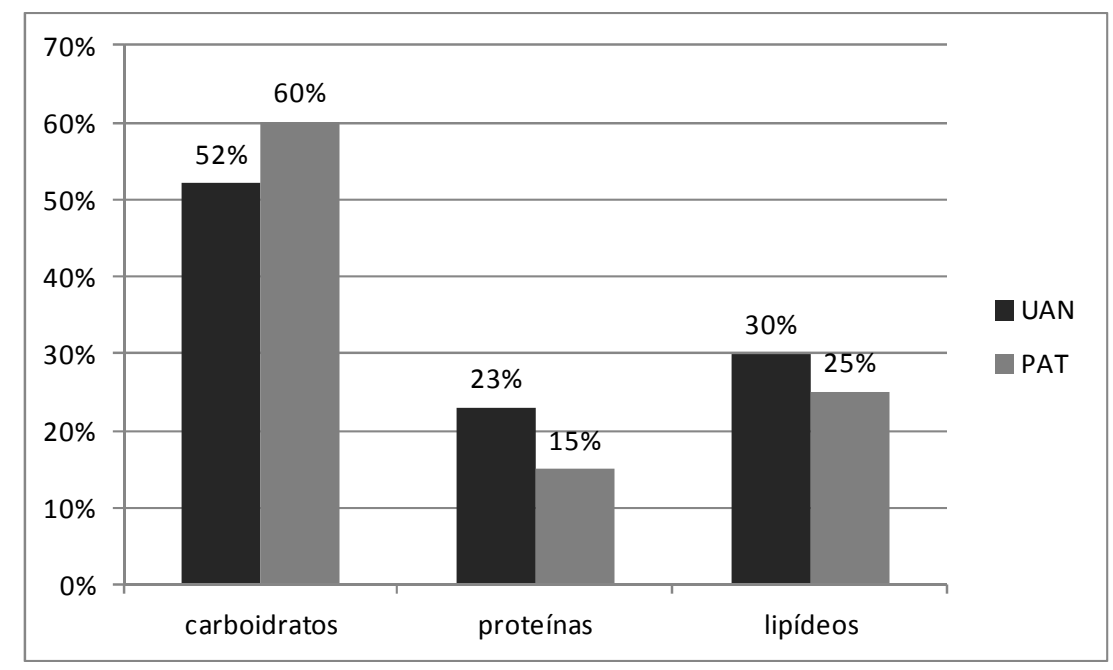

Verifica-se desequilíbrio na oferta de macronutrientes nas refeições.

A oferta média de carboidratos foi relativamente baixa, comparada ao PAT (BRASIL, 2006). A falta de equilíbrio entre os nutrientes oferecidos na refeição também foi observada no estudo de Veloso, Santana e Oliveira (2007), em que as refeições eram ricas em proteínas e gorduras e tinham baixa quantidade de carboidratos.

Tais achados enquadram-se na mudança de padrão alimentar que ocorre no Brasil, onde há uma maior ingestão de carnes, leite e derivados ricos em gorduras e diminuição no consumo de cereais (GERALDO; BANDONI; JAIME, 2008).

A alta ingestão de proteínas está relacionada ao aumento do risco de problemas renais, doenças crônicas e de osteoporose (VANIN et al., 2007; MORAIS; BURGOS, 2007; BRANDÃO; GIOVANONI, 2011).

$\mathrm{O}$ valor de $\mathrm{NdpCal \%} \mathrm{referente} \mathrm{à} \mathrm{porcentagem} \mathrm{de} \mathrm{calorias} \mathrm{advindas} \mathrm{de} \mathrm{fonte} \mathrm{proteica} \mathrm{teve}$ média de 14,3\% - 43\% acima da recomendação (6-10\%.) O NdpCal proporciona uma utilização adequada de proteínas na refeição quando encontra-se no padrão recomendado (SOUSA; SILVA; FERNANDES, 2009).

O consumo de lipídios totais também esteve acima do recomendado, tornando-se preocupante, pois o consumo excessivo de gorduras pode ocasionar dislipidemia e doenças cardiovasculares; assim como, a quantidade de gorduras saturadas que também esteve acima do valor de 10\% preconizado pelo PAT\% (SOUSA; SILVA; FERNANDES, 2009).

Quando observado o valor médio de sódio (613mg), este esteve de acordo com o PAT, que recomenda a quantidade máxima de até $960 \mathrm{mg}$ na refeição almoço. No entanto, esse valor teve variação de $80,5 \%$ ao longo da semana, com valor máximo alcançado em $1595 \mathrm{mg}$, atingindo um valor acima de 960mg em 2 dias na semana avaliada.

O excesso de sódio na dieta pode levar ao desenvolvimento de doenças renais e cardiovasculares, além de estar intrinsecamente relacionado à hipertensão arterial. De acordo com 
dados do IBGE, o consumo individual de sal, apenas nos domicílios brasileiros, foi de 9,6 gramas diários, enquanto o consumo total foi estimado em, aproximadamente, $12 \mathrm{~g}$ diários, o que representa mais do que o dobro do recomendado pela OMS. Com base nessas informações, estima-se que o consumo médio de sal pela população brasileira deve ser reduzido, pelo menos, à metade para atender ao patamar máximo de consumo recomendado, isto é, $5 \mathrm{~g}$ de sal/per capita/dia (BRASIL, 2004; SPINELLI; KAWASHIMA; EGASHIRA, 2011).

O valor médio de fibras dos cardápios excedeu o exigido pelo PAT de 7-10g para as grandes refeições. Estudos apontam que as fibras alimentares têm ação na prevenção e tratamento da doença diverticular do cólon, na redução do risco de câncer, no controle do diabete mellitus, na prevenção da obesidade e de doenças cardiovasculares (NEUTZLING et al., 2007).

Em 2006, os parâmetros nutricionais previstos para o PAT foram revistos, como resposta ao perfil epidemilógico da população adulta brasileira. Essa revisão de parâmetros veio de encontro à preocupação com a obesidade e hipertensão arterial, visto que foram diminuídas as requisições de energia, e incluído um limite para sódio (BRASIL, 2006). A UAN estudada não atendeu, no período avaliado, ambas as recomendações.

Savio et al. (2005) relataram alta prevalência de excesso de peso na população beneficiada pelo PAT. Já, na Bahia, Veloso, Santana e Oliveira (2007) observaram associação entre o aumento de peso e o PAT . Os dados do presente estudo corroboram as observações de que a alimentação em restaurantes inscritos no PAT está associada com o desequilíbrio nutricional dos funcionários beneficiados pelo programa.

Ressalta-se que uma limitação do trabalho foi a não observação da sobra.

\section{CONCLUSÃO}

Concluiu-se haver inadequação do cardápio para oferta de energia, equilíbrio de macronutrientes, gordura saturada, sódio e NdpCal\%, estando em conformidade apenas a oferta de fibras

Dessa forma, é necessária uma melhor elaboração dos cardápios, levando em conta as recomendações nutricionais do PAT. Nesse processo, o nutricionista, com base nas competências relativas à sua formação, tem como função planejar um cardápio que atenda as premissas do PAT, exercendo seu papel como agente de saúde. Dentro desse mesmo contexto, a educação nutricional é essencial para que ocorra uma melhor compreensão do trabalhador sobre a importância da alimentação e sua influência na saúde.

\section{REFERÊNCIAS}

BRANDÃO, A. R.; GIOVANONI, A. C. Comparação dos cardápios oferecidos em uma Unidade de Alimentação e Nutrição do município de Teutônia com o Programa de Alimentação do Trabalhador. Revista Destaques acadêmicos, v. 3, n. 3, pp. 89-94, 2011.

BRASIL. Ministério da Saúde. Gabinete do Ministro. Portaria no 596, de 8 de abril de 2004. Instituir Grupo Técnico Assessor com a finalidade de proceder análise da Estratégia Global sobre Alimentação, Atividade Física e Saúde, da Organização Mundial da Saúde e, em caráter consultivo, 
fornecer subsídios e recomendar ao Ministério da Saúde posição a ser adotada frente ao tema. Diário Oficial da União, Brasília, n. 69, p. 25, 12 abr. 2004. Seção 2.

- Ministério da Saúde. Departamento de Atenção Básica. Guia alimentar para a população brasileira: promovendo a Alimentação Saudável. Brasília: Ministério da Saúde, 2005 (Série A. Normas e Manuais Técnicos).

Ministério do Trabalho e do Emprego. Ministério da Fazenda. Ministério da Saúde. Ministério da Previdência Social e do desenvolvimento social e do combate à fome. Portaria interministerial nº 66, de 25 de agosto de 2006. Diário Oficial da União, Brasília, de 28 de agosto de 2006.

GERALDO, A. P. G; BANDONI, D. H.; JAIME, P. C. Aspectos dietéticos das refeições oferecidas por empresas participantes do Programa de Alimentação do Trabalhador na Cidade de São Paulo, Brasil. Revista Panamericana de Salud Publica, v. 23, n. 1, pp. 19-25, 2008.

GHISLANDI, A. M. P. et al. Adequação dos cardápios da empresa "x" em relação aos novos parâmetros nutricionais do programa de alimentação do trabalhador. Revista de Iniciação Científica, v. 6, n. 1, pp. 1-11, 2008.

JAIME, P. C. et al. Educação nutricional e consumo de frutas e hortaliças: ensaio comunitário controlado. Revista de Saúde Pública, v. 41, n. 1, pp. 154-157, 2007.

MATTOS, P. F. Avaliação da Adequação do Almoço de uma Unidade de Alimentação e Nutrição (UAN) ao Programa de Alimentação do Trabalhador (PAT). Cadernos UniFOA, Volta Redonda, v. 3, n. 7, ago. 2008.

MORAIS, G. Q.; BURGOS, M. G. P. A. Impacto dos nutrientes na saúde óssea: novas tendências. Revista Brasileira de Ortopedia, v. 42, n. 7, pp. 189-194, 2007.

NEUTZLING, M. B. B. et al. Frequência de consumo de dietas ricas em gordura e pobres em fibra entre adolescentes. Revista de Saúde Pública, v. 41, n. 3, pp. 336-342, 2007.

ORNELLAS, L. H. Técnica Dietética: seleção e preparo de alimentos. 8. ed. São Paulo: Atheneu São Paulo, 2006. 296p.

SAVIO, K. E. O. et al. Avaliação do almoço servido a participantes do programa de alimentação do trabalhador. Revista de Saúde Pública, v. 39, n. 2, pp. 148-155, 2005.

SOUSA, F. A; SILVA, R. C. O.; FERNANDES, C. E. Avaliação nutricional de cardápios em unidades de alimentação e nutrição: Adequação ao Programa de Alimentação do Trabalhador. Revista Eletrônica de Ciências, v. 2, n. 1, pp. 43-50, 2009.

SPINELLI, M. G. N.; KAWASHIMA, L. M.; EGASHIRA, E. M. Análise de sódio em preparações habitualmente consumidas em restaurantes self service. Alimentos e Nutrição, v. 22, n. 1, pp. 5561, 2011.

VANIN, M. et al. Adequação nutricional do almoço de uma Unidade de Alimentação e Nutrição de Guarapuava - PR. Revista Salus, v. 1, n. 1, pp. 31-38, 2007.

VELOSO, I. S.; SANTANA, V. S.; OLIVEIRA, N. O Programa de Alimentação do Trabalhador, PAT, e o seu impacto sobre o ganho de peso e sobrepeso. Revista de Saúde Pública, v. 41, n. 5, pp. 769-776, 2007. 